\title{
PERSPECTIVA PARA A RACIONALIDADE AMBIENTAL NO CONTEXTO DA EVOLUÇÃO CTS
}

Perspective for environmental rationality in the context of evolution CTS

\section{Daniela Brusamarelo ${ }^{1}$ Angélica Ramos da Luz ${ }^{2}$}

RESUMO: O presente artigo tem o objetivo de expor os caminhos para uma Educação Ambiental que buscam a promoção de uma nova racionalidade ambiental no cenário econômico e social nos quais evoluem a ciência, a tecnologia e a sociedade. A preocupação com esta evolução no âmbito das questões ambientais faz surgir em alguns países a partir de 1970 a instituição da Educação Ambiental (EA) e o movimento Ciência, Tecnologia e Sociedade (CTS). Os impactos ambientais decorrentes da relação entre a produção, o consumo e o descarte de resíduos, leva ao consenso sobre o perigo à vida planetária. Assim, abordaremos alguns caminhos para uma educação ambiental pautada na promoção de um saber social, integrador, que busca a superação da economia de exploração e a ampliação da compreensão de mundo e de vida.

PALAVRAS-CHAVE: Ambiente; Educação; Evolução tecnológica.

ABSTRACT: This article aims to expose the ways for Environmental Education seeking to promote a new environmental rationality in the economic and social scenario in which evolve the science, technology and society. The concern with these developments in the context of environmental issues raises in some countries since 1970 the establishment of the Environmental Education and the CTS movement. The environmental impacts of the relationship between production, consumption and waste disposal, leads to consensus about the danger to the planetary life. Thus, we will discuss some ways to an environmental education based on the promotion of a knowledge social integrator, seeking to overcome the operating economy and the expansion of understanding of the world and life.

KEYWORDS: Environmental; Education; Technological evolution.

\footnotetext{
${ }^{1}$ Mestranda do curso de Pós-Graduação em Educação para Ciências e Matemática. Instituto Federal de Educação, Ciência e Tecnologia de Goiás- Campus-Jataí. Email: dankerberos@hotmail.com.

${ }^{2}$ Mestranda do curso de Pós-Graduação em Educação para Ciências e Matemática. Instituto Federal de Educação, Ciência e Tecnologia de Goiás- Campus-Jataí. Email: angelica-luz@hotmail.com.br
} 


\section{INTRODUÇÃO}

A relação do homem com o meio ambiente em todas as suas dimensões, no último século, gerou a preocupação global com o futuro da vida no planeta. O desenvolvimento tecnológico, a partir da revolução industrial até a contemporaneidade, tem provocado profundas modificações tanto na natureza quanto no modo de vida das populações. A sociedade mecanicista estabeleceu o sistema capitalista, pautado em uma economia de exploração desmedida de recursos naturais e no consumismo desenfreado de produtos, principalmente de artefatos tecnológicos.

As modificações no ambiente decorrentes da economia vigente evidenciam os rumos da evolução da ciência e da tecnologia com vistas às questões ambientais. O movimento ambiental Ciência, Tecnologia e Sociedade, originado na década de 1970, aponta a educação como instrumento transformador desta realidade e que por meio de uma concepção crítica da sociedade atual a realidade poderá ser modificada (VAZ; FAGUNDES; PINHEIRO, 2009)³.

A Educação Ambiental, por sua vez, é instrumento para a transformação da racionalidade predominante, ao passo que, promove a problematização crítica da realidade e a possibilidade de atuação consciente, ainda na educação básica. Para Loureiro (2012) ${ }^{4}$, as múltiplas esferas da vida planetária e social, debatidas pela EA, visam à produção de um saber dinâmico, que é construído e modificado constantemente por meio de interrogações sobre o mundo, a sociedade, a espécie e o próprio conhecimento.

No âmbito nacional, a Constituição Federal do Brasil, a Lei de Diretrizes e Bases da Educação Nacional (LBD/1996) e as Diretrizes Curriculares Nacionais (DCN), por sua vez preconizam o direito e a obrigatoriedade da EA em todos os níveis de ensino. As DCN, em consonância com a LDB/1996, preveem nos currículos do Ensino Fundamental e Médio a formação básica do cidadão para a compreensão do ambiente natural e social, o conhecimento do mundo físico e natural e a preparação para o exercício da cidadania (BRASIL, 2013) ${ }^{5}$.

\footnotetext{
${ }^{3}$ VAZ, Caroline Rodrigues; FAGUNDES, Alexandre Borges e PINHEIRO, Nilcéia A. Maciel. O surgimento da ciência, tecnologia e sociedade (CTS) na educação: uma revisão. Anais do I Simpósio Nacional de Ensino de Ciência e Tecnologia, Curitiba, 2009. ISBN: 978-85-7014-048-7. http:/ /www.sinect.com.br/anais2009 /artigos/1\%20CTS/CTS_Artigo8.pdf (último acesso em 30/11/15).

${ }^{4}$ LOUREIRO, Carlos Frederico B. Trajetórias e fundamentos da educação ambiental. 4. ed. São Paulo: Cortez, 2012.

${ }^{5}$ BRASIL. Ministério da Educação. Diretrizes curriculares nacionais da educação básica. 2013.

http:/ / portal.mec.gov.br/index.php?option=com_docman \&view=download\&alias=15548-d-c-n-educacao-basicanova-pdf\&It emid=30192 (último acesso em 29/10/2015).
} 
Sendo assim, o objetivo deste artigo de revisão é expor uma breve revisão sobre o contexto econômico e social, a partir da evolução da ciência, tecnologia e sociedade, as implicações ao meio ambiente decorrentes da produção, consumo e descarte de materiais, os caminhos apontados para a EA na perspectiva de uma nova racionalidade ambiental.

\section{Evolução da ciência, tecnologia e sociedade}

A sociedade, ciência e tecnologia se desenvolvem seguindo os pressupostos teóricos e paradigmáticos construídos ao longo da história. O progresso se consolidou, em meados do século XVII, pois a ciência, a filosofia e a economia se voltavam para o mesmo interesse, que era o de estabelecer o domínio do homem sobre a natureza com o predomínio do paradigma mecanicista. Para Ianni (1988, p. 31) ${ }^{6}$, a consolidação do sistema capitalista inglês, no século XVIII, moldado pelo trabalho, pela produção baseada no capitalista e no operário assalariado, universalizou as relações de dependência e alienação, "preparando para o trabalho e para o consumo de tecnologias".

Em decorrência desse cenário surge o movimento denominado CTS que, para Vaz, Fagundes e Pinheiro (2009) advém da preocupação com os rumos da evolução científica e tecnológica no desenvolvimento da sociedade e suas implicações ambientais. Os movimentos ambientais apontam na educação, o meio para inserir na sociedade a concepção crítica concernente a realidade ambiental vivenciada.

É consenso que a ciência, em constante evolução, possibilita o desenvolvimento do progresso. As mudanças decorrentes das tecnologias apresentam novas visões da sociedade para o homem contemporâneo. A ciência e a tecnologia participam e impactam diretamente na organização da sociedade e, para Fourez $(1995)^{7}$, era inconcebível no século XX uma sociedade sem energia, meios de comunicação e artefatos tecnológicos (FOUREZ, 1995) ${ }^{8}$.

No decorrer do avanço científico, a evolução tecnológica, imprime a sua presença no cotidiano da sociedade e necessita de olhar atento das ciências sociais para a compreensão de sua extensão e de seu lugar na sociedade e na história (FONSECA, 2007) ${ }^{9}$. A submissão e passividade a cada exigência tecnológica imposta, a cada novo produto disponibilizado, sem ao menos questionar se este produto agregará valores positivos ou negativos acentuou-se no século XXI. A

\footnotetext{
${ }^{6}$ IANNI, Otávio. Dialética e capitalismo: ensaio sobre o pensamento de Marx. 3. ed. Revista e aumentada em 7 capítulos. Petrópolis-RJ: Vozes, 1988.

${ }^{7}$ FOUREZ, Gerad. A construção das ciências, uma introdução à filosofia e ética das ciências. Trad. de Luiz Paulo Rouanet. São Paulo: Editora Unesp, 1995.

${ }^{8}$ FOUREZ, Gerad. A construção das ciências, uma introdução à filosofia e ética das ciências. Trad. de Luiz Paulo Rouanet. São Paulo: Editora Unesp, 1995.

${ }^{9}$ FONSECA, Alexandre Brasil. Ciência, tecnologia e desigualdade social no Brasil: contribuições da sociologia do conhecimento para a educação em ciências. Revista Eletrónica de Enseñanza de Las Ciências. vol. 6, nº 2, p. 364-377, 2007. http://reec.uvigo.es/volumenes/volumen6/ART8_Vol6_N2.pdf> (último acesso em 13/10/2015).
} 
concepção da sociedade de que são as tecnologias a razão do desenvolvimento têm depositado nos aparatos tecnológicos o motivo de tal evolução. Bazzo $(1998)^{10}$ corrobora afirmando que a tecnologia, de forma cada vez mais frequente, tem se apresentando como uma resposta mesmo que a sociedade não tenha feito nenhuma pergunta.

Essa interação entre sociedade e ciência ocorre de forma diversa. O filósofo Habermas (1973 apud Fourez, 1995) organizou essas interações em três modelos conceituais, o tecnocrático, o decisionista e o pragmático-político, cada qual com suas vantagens e limitações. Dentre estes, o modelo pragmático defende o debate permanente sobre a evolução tecnológica entre especialistas da área e não especialistas, onde na tomada de decisões, por meio de negociações políticas, é levada em consideração a opinião de ambos os lados.

Nesse contexto, a compreensão e a participação da sociedade quanto às tecnologias são fundamentais para o debate recente acerca do condicionamento da existência individual e social à tecnologia. A preocupação é com a dependência que as pessoas têm, "tanto material quanto intelectual", e com os rumos tomados com a evolução das tecnologias (FOUREZ, 1995, p. 219).

A realidade aqui exposta é a de que a sociedade se constrói também com base na tecnologia que desenvolve e esta, por sua vez, transforma os hábitos e as relações desta sociedade. Nessa perspectiva, Bazzo (1998) problematiza que dificilmente se busca estudar e entender a nova sociedade que será formada. E complementa que a sociedade que não compreende a ciência e a tecnologia pouco conseguirá debater e posicionar-se em situações que envolvam a tomada de decisão, imediatas e futuras, e tampouco se aperceberá que a própria ciência é o meio pelo qual ideologias podem ser criticadas e seus limites expostos.

\section{A sociedade consumista: consequências ambientais globais}

O advento do sistema econômico capitalista tem contribuído para aprofundar as modificações ocorridas na natureza e nas práticas sociais da era tecnológica. Os artefatos tecnológicos demandam para a sua fabricação a utilização em grande escala de recursos naturais esgotáveis e, quando descartados de forma inadequada, são contaminantes. Desta realidade decorre a necessidade de repensar a evolução da ciência e da tecnologia com vistas ao desenvolvimento sustentável, as novas formas de socialização e redefinições de identidade cultural e coletiva (VAZ; FAGUNDES; PINHEIRO, 2009).

O consumismo tecnológico é justificado por grande parcela da sociedade contemporânea pelo sentido de liberdade atribuído à tecnologia. Os discursos encontrados são diversos e Bazzo (1998) ilustra exemplificando a defesa do consumo pelo simples fato da tecnologia existir e

\footnotetext{
${ }^{10}$ BAZZO, Walter Antonio. Ciência, tecnologia e sociedade e o contexto da educação tecnológica. Florianópolis: Editora da UFSC, 1998.
} 
apregoar ser, assim como os argumentos de que muitas tecnologias estão plenamente solidificadas em nossa sociedade e em contextos que escapam da nossa capacidade de escolha e controle como, por exemplo, a televisão, os meios de transporte e a energia elétrica.

E some-se a isso

[...] a visão linear de progresso científico-tecnológico não só como um avanço do conhecimento, mas sim como uma melhoria real, inexorável e efetiva em todos os aspectos da vida humana. Desta forma, a ciência e os avanços tecnológicos fariam felizes os homens, independentemente das condições de suas (BAZZO, 1998, p. 117).

As ofertas constantes de versões melhoradas de um mesmo produto culmina com o descarte da tecnologia antecessora, e aumenta as estatísticas de produção de lixo eletrônico do país. O consumismo tecnológico influenciado pelo marketing e a obsolescência programada são fatores contribuintes decisivos para a produção de Resíduo de Equipamento Elétrico e Eletrônico (REE).

O Brasil tem posição de destaque na América Latina enquanto consumidor de produtos eletrônicos, e como o maior produtor dos resíduos decorrentes destes, sendo que este cenário não vislumbra mudanças. O primeiro mapa de lixo eletrônico mundial coordenado pela Organização das Nações Unidas (ONU) apontou o Brasil como responsável pela produção de 1,4 milhão de toneladas de lixo em 2012, dentre as 49 milhões de toneladas produzidas mundialmente. A produção brasileira de lixo eletrônico foi de $7 \mathrm{~kg} /$ habitante $(\mathrm{ONU}, 2012)^{11}$.

A crença predominante na economia clássica de que os recursos naturais estariam disponíveis e seriam facilmente substituíveis desvincula os problemas ambientais e econômicos, e incentiva o consumismo exacerbado de recursos naturais e materiais. A análise de consumo de bens e produtos realizada pelo World Watch Institute (WWI) aponta que em 2006 os 65 países de renda alta detinham $78 \%$ dos gastos, mas representavam apenas $16 \%$ da população mundial. Considerando apenas os Estados Unidos, o gasto foi de $\mathrm{R} \$ 21,8$ trilhões naquele ano, $\mathrm{R} \$$ $72.900,00$ por pessoa, o que corresponde a $32 \%$ dos dispêndios globais feitos por apenas $5 \%$ da população mundial (UMA/WWI, 2010) ${ }^{12}$.

A análise feita na Índia considerando diferentes classes econômicas, de acordo com a WWI em 2009, apontou que mesmo com a renda anual de $\mathrm{R} \$ 4.850,00$ por pessoa em termos de paridade do poder de compra (PPC), muitas residências têm acesso a iluminação básica e um ventilador. Com $\mathrm{R} \$ 9.700,00$ ao ano, o acesso à televisão passa a ser padrão e o acesso a aquecedores de água cresce. Com $\mathrm{R} \$ 15.520,00$ ao ano, a maioria das pessoas dispõe de ampla

\footnotetext{
${ }^{11}$ ONU - Organização das Nações Unidas. E-wasteworldmap. 2012. http://step-initiative.org/index.php/ Overview_Brazil.html (último acesso em 12/07/14).

12 UMA/WWI. WorldwatchInstitute. Estado do Mundo 2010: transformando culturas: do consumismo à sustentabilidade. Relatório anual 2010. 1. ed. Bahia: UMA, 2010. http://www.wwiuma.org.br/estado_2010.pdf (último acesso em 30/11/15).
} 
gama de bens de consumo (UMA/WWI, 2010). O aumento do PPC influencia diretamente na aquisição de novos bens e produtos.

Nesse contexto, a racionalidade econômica baseada na exploração de recursos necessita ser avaliada. Para se ter noção da quantidade de recursos naturais necessários para a produção de tecnologias, na fabricação de um único computador juntamente com seu monitor de 17' (polegadas), ambos pesando em média $24 \mathrm{~kg}$, é utilizado 10 vezes o seu próprio peso em combustível fóssil, aproximadamente $22 \mathrm{~kg}$ de produtos químicos e 1,5 toneladas de água (MATTOS; MATTOS; PERALES, 2008) ${ }^{13}$. Assim, de acordo com os autores, no total, são necessárias aproximadamente 1,8 toneladas de matéria prima para produzir um único computador.

O estímulo ao consumo de bens naturais e materiais aumenta a produção e o descarte de resíduos que impactam o meio ambiente de forma insustentável e leva ao consenso sobre o perigo à vida planetária em toda a sua complexidade. O relatório Estado do Mundo 2013, desenvolvido pela organização WWI apontou como impactos ambientais sérios, os ocasionados principalmente pela emissão de gases poluentes e produção de resíduos: a seca em vários países, a poluição do ar, a desertificação dos solos, o aumento do nível dos oceanos, da emissão de gases do efeito estufa, da temperatura e da migração de populações para outras regiões do planeta (UMA/WWI, 2013) ${ }^{14}$.

O aumento populacional, o desenvolvimento tecnológico e industrial e o processo de urbanização crescente, por sua vez, promovem aumento contínuo na produção per capita de resíduos sólidos. O acúmulo e o descarte de resíduos sólidos orgânicos trazem uma série de problemas ao meio ambiente ao desencadearem eventos que atingem a todas as formas de vida e o funcionamento de todos os ecossistemas. Os resíduos eliminados a céu aberto, e sem o tratamento adequado promovem o desenvolvimento de microorganismos, doenças, produção de líquido percolado (chorume), gases, contaminação de recursos hídricos.

Os resíduos sólidos orgânicos obtidos do consumo e do processamento de alimentos é a categoria que mais contribui em quantidade desperdiçada e descartada no meio ambiente. $\mathrm{O}$ desperdício decorre de fatores como o manuseio inadequado, a falta de condições de armazenagem e transporte, de tecnologias de conservação e principalmente pela má utilização dos

\footnotetext{
${ }^{13}$ MATTOS, Karen Maria da Costa; MATTOS, Katty Maria da Costa; PERALES, Watson José Saenz. Os impactos ambientais causados pelo lixo eletrônico e o uso da logística reversa para minimizar os efeitos causados ao meio ambiente. In: Encontro Nacional de Engenharia de Produção, Rio de Janeiro: Associação Brasileira de Engenharia de Produção, 2008. http://www.abepro.org.br/biblioteca/enegep008_TN_STP_077_543_11709.pdf (último acesso em 05/11/15).

${ }^{14}$ UMA/WWI. WorldwatchInstitute. Estado do Mundo 2013: a sustentabilidade ainda é possível?.Relatório anual 2013. 1. ed. Bahia: UMA, 2013. http://www.akatu.org.br/Content/Akatu/Arquivos / file/EstadodoMundo2013 web.pdf (último acesso em 30/11/15).
} 
alimentos. O lixo se constitui assim em uma problemática dos grandes centros de consumo e acumula-se em toneladas que são produzidas diariamente (ALBUQUERQUE NETO et al., $2007)^{15}$.

O desperdício de alimentos é um fator de prejuízo ambiental e social com sérias consequências. De acordo com o Programa das Nações Unidas para o Meio Ambiente (PNUMA), a quantidade de alimentos produzidos é mais do que suficiente para alimentar toda a população global de forma saudável, mas o desperdício faz com que a produção diária de 4.600 $\mathrm{kcal} /$ pessoa seja revertida num total de $2.000 \mathrm{kcal} /$ pessoa disponíveis para o consumo diário (PNUMA, 2011) ${ }^{16}$. Para o PNUMA, mais da metade dos alimentos produzidos tornam-se lixo orgânico em função do manuseio e infraestrutura inadequados, infestações de pragas em produções agrícolas e de seu mau uso.

A Organização das Nações Unidas para a Agricultura e a Alimentação (FAO) relatou que 1,3 bilhão de toneladas de alimentos é desperdiçada anualmente (FAO, 2013) ${ }^{17}$. De modo que, a produção, o processamento, a comercialização, o consumo e a eliminação de alimentos têm importantes externalidades ambientais. A energia e a utilização de recursos naturais, associados aos gases de efeito estufa ocorrem principalmente durante a fase de produção dos alimentos, e são os mais impactantes para o ambiente. Essas discrepâncias no consumo de alimentos e os padrões de geração de resíduos existem em todo o mundo, sendo premente avaliar o impacto ambiental em nível regional.

O descarte de resíduos sólidos orgânicos na natureza culmina com a geração de gases, líquidos percolados, atração de animais vetores, corrosão de equipamentos e ação de microorganismos patogênicos. Os resíduos lançados em cursos d'água poderão ocasionar assoreamento, o aumento da turbidez e variação de temperatura, acarretando a quebra do ciclo vital das espécies, tornando a água biologicamente estéril. Para Albuquerque Neto et al. (2007), a poluição biológica das águas, a partir de altos índices de coliformes fecais e resíduos que produzem transformações biológicas consideráveis influencia diretamente a qualidade de vida do ecossistema aquático e dos que dele tiram seu sustento.

O aumento da temperatura da superfície do planeta, por sua vez, é resultado direto da exploração e do consumo dos recursos naturais, da queima de combustíveis fósseis, do

\footnotetext{
15 ALBUQUERQUE NETO, Hélio Cavalcanti et al. Caracterização de resíduos sólidos orgânicos produzidos no restaurante universitário de uma instituição pública (estudo de caso). In: Encontro Nacional de Engenharia de Produção, 27, Foz do Iguaçu. Resumos...Foz do Iguaçu: Associação Brasileira de Engenharia de Produção, 2007. http://www.abepro.org.br/biblioteca/enegep200_r650481_0422.pdf (último acesso em 05/10/15).

${ }^{16}$ PNUMA - Programa das Nações Unidas para o Meio Ambiente. Caminhos para o desenvolvimento sustentável e a erradicação da pobreza: síntese para tomadores de decisão. 2011. ISBN: 978-92-807-3204-7. http://www.unep.org/greenconomy (último acesso em 03/08/14).

${ }^{17} \mathrm{FAO}-$ Food and Agricultural Organization. Food wastage footprint: impacts on natural resources. 2013. ISBN 978-92-5-107752-8. http://www.fao.org/docrep/ 018/i3347e/i3347e.pdf (último acesso em 16/10/15).
} 
desenvolvimento tecnológico. Ainda na década de 1970, os países capitalistas e industrializados, responsáveis por utilizar $20 \%$ de toda área agrícola do planeta, afirmavam que a hidrosfera e a atmosfera seriam contaminadas pelos resíduos produzidos no próximo século, considerando uma população de cerca de 10 bilhões de habitantes. No entanto, os 500 milhões de habitantes da Europa Ocidental e da América do Norte causavam neste período tantos impactos para o meio ambiente quanto o fariam possivelmente dez bilhões de indianos (BOSQUET, 1976) ${ }^{18}$.

Os impactos aqui descritos advêm de uma sociedade moldada pelo sistema econômico baseado na exploração de recursos naturais. Esta sociedade consumista não se percebe responsável pela transformação necessária para reverter esse quadro. É fundamental, então, o entendimento de que o consumo de bens naturais, a fabricação e o consumo exacerbado de artefatos tecnológicos e materiais são ações humanas que impactam o meio ambiente de forma complexa, e que por sua vez exigem soluções igualmente complexas (JARROSSON, 1996) ${ }^{19}$.

As consequências impactantes ao meio ambiente causadas pela produção e descarte de resíduos sólidos orgânicos, políticas públicas vigentes e a ordem econômica predominante, denotam a continuidade do processo de produção de resíduos e agressão ao ambiente. A falta de legislação e fiscalização vigente com caráter punitivo dos órgãos responsáveis, de políticas públicas eficazes, de formação em EA que promova um novo entendimento sobre as relações homem e natureza, refletem de forma negativa na qualidade de vida e saúde pública da população, e de todos os organismos vivos que dele dependem. As medidas para a reversão deste quadro necessitam ser repensadas em caráter de urgência.

\section{A educação ambiental e os pressupostos para uma nova racionalidade ambiental}

A sociedade no período pós-guerra estabeleceu o sistema capitalista que se sustenta desde então em uma economia baseada na exploração desmedida de recursos naturais e o consumismo desenfreado de produtos, principalmente de artefatos tecnológicos. O advento deste modelo econômico e político têm contribuído, a partir do último século, para as profundas modificações ocorridas na natureza e nas práticas sociais da sociedade tecnológica.

É nesse contexto que, por volta da década de 1960, a sociedade busca compreender as mudanças provocadas desde então, principalmente as ambientais. A necessária compreensão do que passou a ocorrer nesse período faz surgir o conceito de desenvolvimento sustentável e os princípios para a EA. Esta tomada de consciência ambiental se iniciou na década de 1960, e expandiu-se para as décadas seguintes sendo relevante para esse entendimento a Conferência das

\footnotetext{
18 BOSQUET, Michel. Ecologia e Política.Lisboa: Editorial Notícias, 1976.

${ }^{19}$ JARROSSON, Bruno. Humanismo e técnica: o humanismo entre economia, filosofia e ciência. Trad. De Isabel de Almeida Brito. Lisboa: Instituto Piaget, 1996.
} 
Nações Unidas para o Meio Ambiente, em Estocolmo no ano de 1970 e a Conferência de Tbilisi, na Geórgia em 1977, que estabeleceu as diretrizes e orientações para a EA.

A educação formal é reconhecidamente instrumento que promove a transformação social, e por meio dela, entendemos que é possível que a racionalidade econômica se efetive, sendo a EA um caminho para esta efetivação. No entanto, no sistema formal de ensino brasileiro ainda necessitamos percorrer um longo caminho para isto. No cenário nacional tanto a Constituição Federal, as Diretrizes Curriculares Nacionais (DCN) e a Lei de Diretrizes e Bases da Educação Nacional (LBD/1996) preconizam o direito e obrigatoriedade da EA em todos os níveis de ensino. A Política Nacional de Educação Ambiental (PNEA), instituída em 1999, por sua vez caracteriza e Educação Ambiental Formal (EAF), realizada nas instituições de ensino oficiais, e a Educação Ambiental Não Formal (EANF), realizada nos diversos segmentos da sociedade (BRASIL, 1999) ${ }^{20}$.

A EA pretendida para essa transformação é a que promova a racionalidade ambiental, a cidadania, a sustentabilidade e a complexidade (LEFF, 2013) ${ }^{21}$. Em outras palavras, o saber ambiental em que as práticas sociais, as regras, o meio e os fins são socialmente construídos; demonstrando a necessidade de integrar os conhecimentos que são fragmentados, e com abertura para uma nova racionalidade social e a reconfiguração da economia vigente. Para esse saber, o aluno é um sujeito inserido em uma realidade que é local, regional, global, ideológica e social. A construção do conhecimento é considerada na relação sujeito e sua realidade socioambiental, inter-relacionada e interconectada.

Nesse sentido, essa nova racionalidade ambiental conduz a novos pensamentos e novas atitudes em relação ao ambiente. Isso significa, além do exposto acima, transcender políticas que se ocupam da conservação, descontaminação e restauração ecológica, para políticas sustentáveis que considerem a equidade social, a diversidade cultural, a gestão democrática e a pluralidade de desenvolvimentos; superar uma economia que nega a natureza, para uma racionalidade pautada em novas bases, novos equilíbrios ecológicos, novo valor da natureza e fortalecedora das economias locais e regionais.

No âmbito da CTS, ao considerar a EA como um caminho possível para a compreensão da sua real necessidade e importância perante a sociedade, é necessário que o enfoque da didática seja mais intenso. Para Bazzo (1998) não se trata somente de avaliar os possíveis impactos ocasionados pela tecnologia em nossas vidas, mas descobrir a quais caminhos irreversíveis elas nos conduzirão. Há um consenso entre autores de que deveriam existir níveis mínimos de

${ }^{20}$ BRASIL. Ministério da Educação. Política Nacional de Educação Ambiental. Brasília, 1999. http://www.planalto.gov.br/ccivil_03/LEIS/L9795.htm (último acesso em 22/04/2016).

${ }^{21}$ LEFF, Enrique. Saber ambiental: sustentabilidade, racionalidade, complexidade, poder. Trad. Lúcia Mathilde Endlich Orth. 10. ed. Rio de Janeiro: Vozes, 2013. 
aprendizagem sobre a tecnologia para todos os estudantes, em que o estudo da ciência deve estar conectado ao da tecnologia e suas consequências sociais.

A escola se constitui, então, em espaço para a criatividade, a curiosidade e ainda, para a compreensão de como o ser humano se constitui, se organiza socialmente e se integra a natureza. Enquanto prática social potencializa os questionamentos e reflexões sobre a realidade em um processo de crítica, autocrítica, política e conscientização coletiva. A EA, por sua vez, integra a educação buscando contrapor concepções e tendência solidificadas, entender e viabilizar novos patamares societários e civilizacionais (LOUREIRO, 2012).

Neste contexto, a aprendizagem das ciências, em seu conceito amplo, necessita potencializar o espírito crítico do educando de forma profunda. Para isso, Cachapuz et al. (2005, p. 27) ${ }^{22}$ afirma ser preciso "superar concepções distorcidas e empobrecidas da ciência e da tecnologia", que são socialmente aceitas e que afetam o educador. O autor complementa que, no âmbito educacional, deve ser priorizado na formação dos educandos oportunidades para "analisar a situação de emergência que se encontra o planeta e considerar as possíveis soluções" CACHAPUZ et al., 2005, p. 28).

A formação crítica do cidadão, com entendimento e reconhecimento profundo da sua relação com o meio ambiente, se faz necessária ainda na formação básica. O desenvolvimento de habilidades mentais é premente para perceber a dinâmica econômica da sociedade que leva ao consumo acelerado de tecnologias, a obsolescência programada dos equipamentos, as estratégias de marketing, que trazem como importante consequência o acúmulo de lixo. Transformar a concepção de uma sociedade que acredita que quanto maior for à produção científica e tecnológica do país, maior será a geração de riquezas e por consequência o bem-estar social (VAZ; FAGUNDES; PINHEIRO, 2009).

Para promover essa transformação, a problemática ambiental na educação envolve a concepção integrada de processos históricos, econômicos, sociais, políticos, tecnológicos, ecológicos e culturais. De acordo com Leff $(2002)^{23}$, para a construção de uma racionalidade ambiental e produtiva é necessário primeiro diagnosticar os efeitos dos processos de reprodução e acúmulo de capital, os impactos ambientais das práticas atuais de produção e consumo e a formação social dos países em desenvolvimento e a valorização da exploração de seus recursos.

A efetivação desta nova racionalidade ambiental ocorre por meio da articulação subjetiva do educando com a produção de conhecimentos para que este se perceba inserido em uma realidade socioambiental. Leff (2013) aponta que o caminho da transdisciplinaridade e a iniciação à pesquisa possibilitam o entrelaçar de conteúdos e práticas pedagógicas considerando a busca da

${ }^{22}$ CACHAPUZ, Antonio et al.(Orgs.). A renovação necessária do ensino de ciências. São Paulo: Cortez, 2005.

${ }^{23}$ LEFF, Enrique. Epistemologia ambiental. Trad. Sandra Valenzuela. 5. ed. São Paulo: Cortez, 2002. 
compreensão e de soluções para a complexidade das relações entre sociedade, economia e natureza o que demanda, por sua vez, fomentar o pensamento crítico, reflexivo e propositivo.

Assim, a reorientação epistemológica para a educação ambiental com vistas ao desenvolvimento futuro é primordial. A pedagogia do ambiente vinculada à concepção da complexidade junto ao educando, induzirá e fomentará habilidades mentais para ampliar a concepção que se tem de ambiente e a compreensão do mundo como sistemas complexos, interdependentes e interconectados com os diferentes processos (LEFF, 2013).

Convém considerar, ainda, que a essência da EA, para além de considerar a educação para o meio ambiente ou em prol deste, é fundamentalmente a relação entre a sociedade e a natureza. Assim, o educador, para intervir adequadamente, necessita considerar as diversas concepções de EA e as múltiplas facetas que compõe essa relação (SAUVÈ, 2005) ${ }^{24}$.

O desenvolvimento de habilidades na formação básica do educando é necessária para perceber a dinâmica desta sociedade que leva ao consumo acelerado de recursos naturais e de tecnologias, a obsolescência programada dos equipamentos, as estratégias de marketing, que trazem como importante consequência o esgotamento de recursos naturais, a degradação de ecossistemas, o acúmulo de resíduos.

Para uma EA transformadora social dessa realidade é fundamental o exercício do diálogo, da cidadania, do fortalecimento do sujeito. A emancipação da sociedade passa pela superação das formas de dominação capitalistas, e pela compreensão do mundo como um sistema complexo, em que todos os processos que o compõe estão inter-relacionados (LOUREIRO, 2012).

Nessa perspectiva, um conjunto de processos sociais deve ser considerado pelo todo, dentre eles, a formação de consciência ecológica, a participação da sociedade na gestão de recursos ambientais, o planejamento da administração pública e a reorganização interdisciplinar do saber, tanto na produção quanto na aplicação do conhecimento (LEFF, 2013).

Assim, a reflexão sobre o papel que se tem atribuído à educação e suas implicações na sociedade tem se mostrado como o caminho para as transformações sociais, políticas e econômicas, necessárias para o desenvolvimento de uma nova racionalidade ambiental. Dessa forma, a reflexão sobre a finalidade do ensino se faz necessária, pois "[...] a educação retrata e reproduz a sociedade; mas também projeta a sociedade que se quer. Por isso, vincula-se profundamente ao processo civilizatório e humano. Enquanto prática histórica tem o desafio de responder às demandas que os contextos lhe colocam" (PIMENTA, 2012, p. 44) ${ }^{25}$.

\footnotetext{
${ }^{24}$ SAUVÈ, Lucie. Uma cartografia das correntes em Educação Ambiental. In: SATO, Michèle; CARVALHO, Isabel C. Moura (Orgs.). Educação Ambiental. Porto Alegre: Artmed, 2005, p. 17 - 44.

${ }^{25}$ PIMENTA, Selma Garrido (Org.). Professor Reflexivo: construindo uma crítica. In: PIMENTA, Selma Garrido et al. (Org.). Professor reflexivo no Brasil: gênese e crítica de um conceito.7. ed. São Paulo: Cortez, 2012. p. $20-63$.
} 


\section{Considerações finais}

A sociedade se constitui como produtora e consumidora de bens materiais em uma economia baseada na exploração de recursos naturais. $O$ consumismo, principalmente de artefatos tecnológicos, poderá aumentar proporcionalmente em função da elevação da renda per capita do indivíduo e os impactos ambientais gerados pela produção e descarte inadequado de resíduos comprometem todas as formas de vida no planeta.

O movimento CTS e a EA contribuem para o estímulo ao pensamento crítico e reflexivo do educando para a construção de uma nova racionalidade, que não conceba a ciência e a tecnologia meramente a serviço do desenvolvimento econômico, mas como possibilidade para considerar a sustentabilidade dos processos com vistas ao desenvolvimento futuro.

A educação que retrata e reproduz a sociedade também projeta o futuro pretendido. Constitui-se em motor da mudança para a transformação social ao considerar o conjunto das dinâmicas que envolvem as esferas cultural, ecológica, econômica, tecnológica e política. As mudanças almejadas na escola envolvem todo o ambiente educacional e devem estar integradas aos demais segmentos da sociedade.

A Educação Ambiental é o instrumento para o desenvolvimento de uma nova racionalidade ambiental, o entendimento do sujeito em sua relação com a natureza, o exercício da cidadania, a defesa dos princípios da solidariedade, igualdade e diversidade, a apreensão de que um desenvolvimento sustentável será possível somente a partir do rompimento com o pensamento racionalista econômico dominante.

\section{REFERÊNCIAS}

ALBUQUERQUE NETO, Hélio Cavalcanti et al. Caracterização de resíduos sólidos orgânicos produzidos no restaurante universitário de uma instituição pública (estudo de caso). In: Encontro Nacional de Engenharia de Produção, 27, Foz do Iguaçu. Resumos...Foz do Iguaçu: Associação Brasileira de Engenharia de Produção, 2007.

http://www.abepro.org.br/biblioteca/enegep200_r650481_0422.pdf (último acesso em 05/10/15).

BAZZO, Walter Antonio. Ciência, tecnologia e sociedade e o contexto da educação tecnológica. Florianópolis: Editora da UFSC, 1998.

BOSQUET, Michel. Ecologia e Política.Lisboa: Editorial Notícias, 1976.

BRASIL. Ministério da Educação. Diretrizes curriculares nacionais da educação básica. 2013. http://portal.mec.gov.br/index.php?option=com_docman $\&$ view $=$ download\&alias $=15548$-d-c-n-educacao-basica-nova-pdf\&It emid=30192 $>$ (último acesso em 29/10/2015).

. Ministério da Educação. Política Nacional de Educação Ambiental. Brasília, 1999. http://www.planalto.gov.br/ccivil_03/LEIS/L9795.htm (último acesso em 22/04/2016). 
CACHAPUZ, Antonio et al.(Orgs.). A renovação necessária do ensino de ciências. São Paulo: Cortez, 2005.

FONSECA, Alexandre Brasil. Ciência, tecnologia e desigualdade social no Brasil: contribuições da sociologia do conhecimento para a educação em ciências. Revista Eletrónica de Enseñanza de Las Ciências. vol. 6, $\mathrm{n}^{\circ}$ 2, p. 364-377, 2007.

http://reec.uvigo.es/volumenes/volumen6/ART8_Vol6_N2.pdf (último acesso em: $13 / 10 / 2015)$.

FAO - Food and Agricultural Organization. Food wastage footprint: impacts on natural resources. 2013. ISBN 978-92-5-107752-8. Disponível em: <http://www.fao.org/docrep/ 018/i3347e/i3347e.pdf>, acesso em: 16/10/15.

FOUREZ, Gerad. A construção das ciências, uma introdução à filosofia e ética das ciências. Trad. de Luiz Paulo Rouanet. São Paulo: Editora Unesp, 1995.

IANNI, Otávio. Dialética e capitalismo: ensaio sobre o pensamento de Marx. 3. ed. Revista e aumentada em 7 capítulos. Petrópolis-RJ: Vozes, 1988.

JARROSSON, Bruno. Humanismo e técnica: o humanismo entre economia, filosofia e ciência. Trad. De Isabel de Almeida Brito. Lisboa: Instituto Piaget, 1996.

LEFF, Enrique. Saber ambiental: sustentabilidade, racionalidade, complexidade, poder. Trad. Lúcia Mathilde Endlich Orth. 10. ed. Rio de Janeiro: Vozes, 2013.

Epistemologia ambiental. Trad. Sandra Valenzuela. 5. ed. São Paulo: Cortez, 2002.

LOUREIRO, Carlos Frederico B. Trajetórias e fundamentos da educação ambiental. 4. ed. São Paulo: Cortez, 2012.

MATTOS, Karen Maria da Costa; MATTOOS, Katty Maria da Costa; PERALES, Watson José Saenz. Os impactos ambientais causados pelo lixo eletrônico e o uso da logística reversa para minimizar os efeitos causados ao meio ambiente. In: Encontro Nacional de Engenharia de Produção, Rio de Janeiro: Associação Brasileira de Engenharia de Produção, 2008. http://www.abepro.org.br/biblioteca/enegep008_TN_STP_077_543_11709.pdf (último acesso em $05 / 11 / 15)$.

ONU - Organização das Nações Unidas. E-wasteworldmap. 2012. http://stepinitiative.org/index.php/Overview_Brazil.html (último acesso em 12/07/14).

PIMENTA, Selma Garrido (Org.). Professor Reflexivo: construindo uma crítica. In: PIMENTA, Selma Garrido et al. (Org.). Professor reflexivo no Brasil: gênese e crítica de um conceito.7. ed. São Paulo: Cortez, 2012. p. 20-63.

PNUMA - Programa das Nações Unidas para o Meio Ambiente. Caminhos para o desenvolvimento sustentável e a erradicação da pobreza: síntese para tomadores de decisão. 2011. ISBN: 978-92-807-3204-7. http://www.unep.org/greenconomy (último acesso em 03/08/14). 
SAUVÈ, Lucie. Uma cartografia das correntes em Educação Ambiental. In: SATO, Michèle; CARVALHO, Isabel C. Moura (Orgs.). Educação Ambiental. Porto Alegre: Artmed, 2005, p. 17- 44.

UMA/WWI. WorldwatchInstitute. Estado do Mundo 2013: a sustentabilidade ainda é possível?. Relatório anual 2013. 1. ed. Bahia: UMA, 2013.

http://www.akatu.org.br/Content/Akatu/Arquivos/file/EstadodoMundo2013web.pdf (último acesso em 30/11/15).

Estado do Mundo 2010: transformando culturas: do consumismo à sustentabilidade.

Relatório anual 2010. 1. ed. Bahia: UMA, 2010. http://www.wwiuma.org.br/estado_2010.pdf (último acesso em 30/11/15).

VAZ, Caroline Rodrigues; FAGUNDES, Alexandre Borges e PINHEIRO, Nilcéia A. Maciel. O surgimento da ciência, tecnologia e sociedade (CTS) na educação: uma revisão. Anais do I

Simpósio Nacional de Ensino de Ciência e Tecnologia, Curitiba, 2009. ISBN: 978-85-7014048-7. http://www.sinect.com.br/anais2009 /artigos/1\%20CTS/CTS_Artigo8.pdf (último acesso em 30/11/15). 